\title{
REPERTORIUM VAN LITERATUUR OP HET GEBIED VAN ACCOUNTANCY EN BEDRIJFSHUISHOUDKUNDE
}

Redactie: Stichting Centrale Dienst voor Bedrijfsdocumentatie

\section{TIJDSCHRIFTENREPERTORIUM}

\section{B. BEDRIJFSHUISHOUDKUNDE}

\section{a. ALGEMENE BEDRIJFSHUISHOUDKUNDE}

\section{WAARNEMINGSMIDDELEN}

De bedrijfsstatistiek van het eigen vervoer en de vraagstukken bij invoering eraan verbonden

Assem, J. W. van - De schrijver geeft een opsomming van de verschillende gegevens, welke moeten worden verzameld bij de invoering van bedoelde statistiek. Deze gegevens worden verzameld op het tijdbriefje. De heer van $A$. bespreekt de indeling hiervan.

B a III 2

Bedrijfsvervoer 27, No. 3, 1948

\section{Variabele budgettering}

Vee nendaal, G. J. - Eerste gedeelte van een résumé van een voordracht. Schrijver noemt vier aspecten der budgettering, doch behandelt alleen het bedrijfseconomische. Korte historische schets over de taak der administratie, gevolgd door een bespreking van verschillende budgetten, die in een onderneming moeten worden opgesteld. Hierbij wordt uitgegaan van het verkoopbudget, terwijl de kosten afhankelijk worden gesteld van de opbrengsten. Het productiebudget wordt afgeleid uit de afzetbegroting, waarbij nog een onderscheid wordt gemaakt tussen productie op voorraad en productie op bestelling.

B a III 3 Financieel Overheidsbeheer Jrg. 23, No. 2, 15 Februari 1948

\section{De administratie van het productieproces}

$P$ rause, F. J. - Het is van belang, dat in een fabriek bij het vervaardigen van een stuk of een serie, de tijd, waarin het klaar komt, de arbeiders, die er aan werken, de machines die gebruikt worden enz., nauwkeurig worden aangetekend. De heer Prause geeft enige voorbeelden daarvan.

B a III 3

Het Moderne Bedrijfsleven 11, No. 5, 1948

\section{LEER VAN DE KOSTPRIJS}

De ondernemingsbelasting als last van het jaar waarover zij wordt berekend

Hendriks, H. E. F. - Schr. geeft een methode om de ondernemersbelasting ten laste te brengen van het jaar waarover zij wordt berekend. Dit zal volgens het betoog voornamelijk ten voordele zijn van die onderneming, die in de opeenvolgende jaren belangrijke winstfluctuaties kennen (in redactionele noot wordt nagegaan in hoeverre de belastingautoriteiten deze berekeningswijze zullen accepteren). B a IV 7

Maandblad voor Belastingrecht Jrg. 16, No. 5, Maart 1948

\section{Enige opmerkingen over de grondslagen der vervangingswaardetheorie}

Me y, Dr J. L. - In het Januari-nummer van "De Economist" heeft de heer van Hensbergen critiek geleverd op de vervangingswaardetheorie, in het bijzonder zoals die is weergegeven in het boek van $\mathrm{Dr}$ Mey "Leerboek der Bedrijfshuishoudkunde". Volgens van Hensbergen zou het positieve en normatieve deel der bedrijfseconomie niet voldoende worden onderscheiden. Verder verwijt hij de aanhangers der vervangingswaardeleer, dat te weinig waardering voor de Oostenrijkse waardeleer aan de dag wordt gelegd. Dr Mey gaat op een en ander uitvoering in en maakt van deze gelegenheid gebruik om nog eens te wijzen op de grondslagen der vervangingswaardetheorie.

B a IV 2

De Economist 96, No. 4, 1948: 


\section{Toepassing der belastingwetten}

Adriani, P. I. A. - Korte, heldere en belangwekkende uiteenzetting aan de hand van de laatste arresten. Wat is te verstaan onder bedrijf? Hoe rekent de fiscus bij overgang van vermogensbestanddelen naar privé en omgekeerd? Wat is bedrijf, wat is particulier vermogen. Wat is het gedrag van de fiscus ten aanzien van de bij liquidatie vrijkomende stille reserves? (met vermelding van de arrestnummers en data). De invloed der belastingrechtswetenschappelijke opvatting omtrent de begrippen vermogen en winst op de berekening der belastingen.

B a IV 7 Weekblad voor privaatrecht, notarisambt en registratie Jrg. 7, No. 4023,

28 Februari 1948

\section{Theorie van de dividendpolitiek}

B e r k u m, P. P. va n - In de dividendbepalende balans concurreren de verschillende alternatieve winstaanwendingsmogelijkheden. Het dividend verleden en de verwachtingen van toekomstig dividend vormen een criterium voor de credietwaardigheid van de onderneming. Daardoor tegenwoordig weigering tot dividendstabilisatie. Schr. behandelt de houding van de practijk en stelt daar zijn opvattingen tegenover (Eerste van een serie artikelen).

B a IV 8

Economie Jrg. 12, No. 6/7, Maart/April 1948

\section{Berekening bij Goodwill}

Andriese, G. - Berekeningsmethoden voor de bepaling van de goodwill. Deze wordt hier uitgevoerd ter bepaling van de uitkoopsom, zijnde de gekapitaliseerde basiswinst vermenigvuldigd met een correctiefactor. Deze correctiefastor is afhankelijk van het aantal toekomstige winsten, het toekomstig verloop van deze winsten en de rente. voet. Schr, is voorstander van het in de berekening betrekken van zowel de economische als de technische levensduur van de te berekenen waarden. Voorts wordt gegeven een model van een afschrijvingsplan voor de goodwill.

B a IV 8

De Naamloze Vennootschap Jrg. 25, No. 11, Febr. 1948

\section{LEER VAN DE FINANCIERING}

\section{Baas in eigen huis}

$\mathrm{S}$ c h l i n g e n m a n n, J. G. - Door belastingpolitiek tot uitgangspunt te maken - dus vorming van overgrote stille reserves - zijn de aandelen van de eenmans- en familievennootschappen op de aandelenmarkt ondergewaardeerd. Door hoge kapitaaleisen is interne financiering vaak niet meer mogelijk. Bij de emissie zou openbaarmaking der werkelijke stand nodig zijn en krijgt men te doen met de heffing der vermogensaanwas, of indien slechts een gedeelte der stille reserves zou worden geopenbaard, geeft men aan de nieuwe aandeelhouders een deel der stille reserves. Preferente aandelen zijn niet en vogue. Tracht men onderhand kapitaal te verkrijgen dan verliest men een groot deel van de zeggenschap over het bedrijf. Schr. verdedigt tegenover de fiscale overheid uitzonderingstarieven voor dergelijke ondernemingen.

B a V 1 Economisch Statistische Berichten Jrg. 33, No. 1610, 17 Maart 1948

\section{Wat verstaat men onder bijzondere financieringsregeling?}

R a s, L. F. - In geval van toepassing hiervan stelt de Staat zich jegens de Maatschappij tot Financiering van het Nationaal Herstel N.V. garant voor een gedeelte van de verplichtingen, welke de betreffende onderneming moet aangaan, om het verschil in de kosten van herstel aan de ene kant en de rijksbijdrage en molestpenningen aan de andere kant te overbruggen. Het doel van deze regeling is de remmende invloed welke van prijsdaling op het herstel uitgaat op te vangen. Een en ander wordt uitvoerig besproken.

B a V 1, Maandblad voor Accountancy en Bedrijlshuishoudkunde 22, No. 4, 1948

\section{Bedrijfsfinanciering}

Redactie - Vele ondernemers zien zich geplaatst voor de vraag of zij hun werkkapitaal zullen uitbreiden of niet. Enkele mogelijkheden worden besproken en de vooren nadelen opgesomd. De overheid dient echter onder alle omstandigheden een gunstig klimaat te scheppen door het toestaan van afschrijvingen op basis der vervangingswaarde.

$\mathrm{B}$ a $\mathrm{V} 1$

De Industrie 3, No. 11, 1 Juni 1948 
De Emissie van de Koninklijke en de theorie van de expansie-reserve

Vliet, P. G. van de - In het Januari-nummer van dit blad toetste Dr J. L. Mey de theorie van de expansie-reserve aan de Emissie van de Koninklijke en constateerde, dat de berekening volgens de in het handelsrekenen gebruikelijke wijze niet tot een juiste claimwaarde leidt. In dit artikel poogt $\mathrm{Dr}$ van de Vliet de laatste bewering te weerleggen. In zijn antwoord zegt Dr Mey, dat Dr van de Vliet niets anders doet dan de gedachten, welke aan de theorie van de expansie-reserve ten grondslag ligt toepassen.

B a V 3

Maandblad voor Bedrijfsadministratie 52, No. 613, 1948

\section{LEER VAN DE ORGANISATIE}

\section{Bedrijfsbezoeken als milldel tot efficiencyverhoging}

Kroes, H. - Het weinige voordeel dat over het algemeen de kleine bedrijven van het efficiencywerk dat in ons land is verricht, trekken - meestal door tijdsgebrek der leiding - zou kunnen worden vergroot door het organiseren van bedrijfsbezoeken. In dit artikel worden de verwachte resultaten besproken en de wijze van organisatie deze bedrijfsbezoeken - die reeds in sommige bedrijven plaatsvonden - nader toegelicht.

B a VI 1 Tijdschrift voor Efficiency en Documentatie Jrg. 18, No. 3, Maart 1948

Het huisorgaan als onderdeel der gerichte reclame

Herpen, E. van - Het belang van het huisorgaan en de wijze, waarop het samengesteld moet worden om doeltreffend te zijn.

B a VI 11

Revue der Reclame 8, No, 2, 1948

\section{Marktonderzoek toegepast in de reclame}

Vreede, Th. - De heer Vreede bespreekt achtereenvolgens de volgende punten: 1. Grondslagen marktonderzoek; 2. Omvang; 3. Eis en steekproef; 4. Graad van nauwkeurigheid; 5. Enquèteursstaf; 6 . Systematiek en methodiek. Daarna gaat hij over tot de bespreking van de toepassing van marktonderzoek op het gebied der reclame. De volgende punten komen ter sprake: 1. Persreclame. Het gaat om de keuze van het orgaan; 2. Buitenreclame; 3. Bioscoopreclame. Bij 2 en 3 gaat het om de beoordeling van het kwalitatief effect; 4 . Beīnvloedingsfactoren. De schrijver noemt enkele factoren, welke het resultaat kunnen beïnvloeden; 5. Planning.

$\mathrm{B}$ a VI 12

Revue der Reclame 8, No. 2, 1948

\section{Communicatiesystemen}

Redactie - Nieuwe Amerikaanse uitvindingen op het gebied van de communicatie. 1e. Amplicall. Deze heeft maximaal 24 hoofdtoestellen, maximaal één hoofdtoestel en één neventoestel. Met een hoofdtoestel kan met leder ander hoofd- of neventoestel in een willekeurige plaats een gesprek voeren, een neventoestel kan alleen een hoofdtoestel bereiken. 2e. De Call-Master heeft een uitvoering, die bijna gelijk is aan die van de Amplicall, maar heeft maximaal zeven hoofdtoestellen of zes neventoestellen. 3e. Convers-O-Call. Op zijn hoogst zijn er 30 hoofdtoestellen. Een eenvoudiger heeft 1 hoofdtoestel en maximaal 10 neventoestellen. 4e. Executone. Door combinatie en groepen kunnen 100 toestellen worden bediend.

5e. Flash-a-call. De grootste installatie heeft 10 hoofdtoestellen en 15 neventoestellen. 6e. Masco. Eén hoofdtoestel en 4 neventoestellen, of maximaal 5 hoofdtoestellen. Evenals bij de Flash-a-call kan de geluidsterkte worden geregeld. 7e. Talk-a-Phone. Door combinatie kan men een installatie van 100 toestellen krijgen. Be. A.A.C. In één groep kunnen maximaal 13 hoofdtoestellen, of één hoofdtoestel en 12 neventoestellen geschakeld worden.

B a VI 13

Kantoormachinenieuws 3, No. 5, 1948

\section{Controleklokken}

Redactie $-1^{\circ}$. De Federal tijd- en contrōleklokken. Deze zijn in drie modellen leverbaar. De kaarten kunnen verschillende afmetingen hebben en de kaartentrechter verschuift automatisch in de juiste kolom- en datumpositie. Bij de Sederal kan een automatisch signaal voor het regelen van tijdsignalen aangebracht worden.

$2^{\circ}$. De Printime is een electrische datum- en tijdstempel, waarbij men slechts de knop van het apparaat heeft neer te drukken om een afdruk te verkrijgen.

B a VI 13

Kantoormachinenieuws 3, No. 5, 1948 


\section{De functie van de econometrie bij het bedrijfsbeheer}

Dalmulder, J. J. J. - A mere theoretical discussion about the nature of econometrics and an analysis of the application in industrial and commercial management, specially from a statistical point of view.

B a VI 13

Statistica 2, No. 1/2,1947/48

\section{Functie-analyse}

Matthysen, J. M. - Aan de eisen van efficiency kan het best voldaan worden, wanneer iedere arbeider een taak heeft, die bij hem past. Om dat te bereiken zij nodig: 1e. Functie-analyse, waarbij het werk ontleed wordt, zodat bepaald kan worden, welke eigenschappen en capaciteiten vereist zijn. Ook kunnen hierdoor promotielijnen uitgestippeld worden. 2e. Psychotechnisch onderzoek van de in dienst te nemen arbeider. Functie-analyse is ook nodig om het werk te kunnen classificeren, wat van belang is voor de loonregeling.

$\mathrm{B}$ a VI 13 Tijdschrift voor Elficiency en Docmuentatie 18, No, 5, 1948

De ondernemingsraad in de publiekrechtelijke bedrijfsorganisatie

Vera a rt, J. A. - De schrijver ziet de ondernemingsraad in het kader der verticale bedrijfsorganisatie, hiërarchisch ondergeschikt aan de bedrijfsraad. Hij gaat in op beider bevoegdheden, welke hun begrenzing vinden in de doelmatigheid. Hij eindigt met een bespreking van de positie der ondernemer. In het kader der publiekrechtelijke bedrijfsorganisatie is deze in wezen constitutioneel. Prof. Veraart stelt de vraag, of het wenselijk is de mogelijkheid te scheppen een onbekwaam ondernemer uit te schakelen. B a VI $14 \quad$ Tijdschrift voor Efficiency en Documentatie 18, No. 5, 1948

\section{Niedezeggenschap}

S l o t e make r, B. C. - Hoewel het lang geduurd heeft voordat er een bevredigende oplossing was voor het vraagstuk ,de medezeggenschap van de werknemer" meent men dat deze nu toch gevonden is. Ook de moeilijkheden, die hieraan zijn voorafgegaan worden in dit artikel beschreven.

B a VI 14 Tijdschrift voor Efficiency en Documentatie 18, No. 5, Mei 1948

\section{Les risques dans l'entreprise privée}

$\mathrm{Urbain}, \mathrm{V}$ a es - Etude des causes générales des risques. Causes naturelles. Causes humaines d'orde physiologiques d'opposition d'interêts, de déficiences de l'organisation économique général comme les risques de conjuncture et les risques monétaires, de progres de la science et l'état de la population, d'insuffisance de l'organisation interne. Classification des risques selon leurs caracteristiques suivie par un bref examen de leur localisation. Résumé sommaire de moyens générales employés pour combattre les risques dispositions préventives, mesures éclairants et de vérification, mesures compensatoires comme l'assurance extérieure et intérieure. Les risques de l'entreprise privee.

B a VI 14 Annales de sciences économiques appliquées Louvain Année 6, No. 1 , 